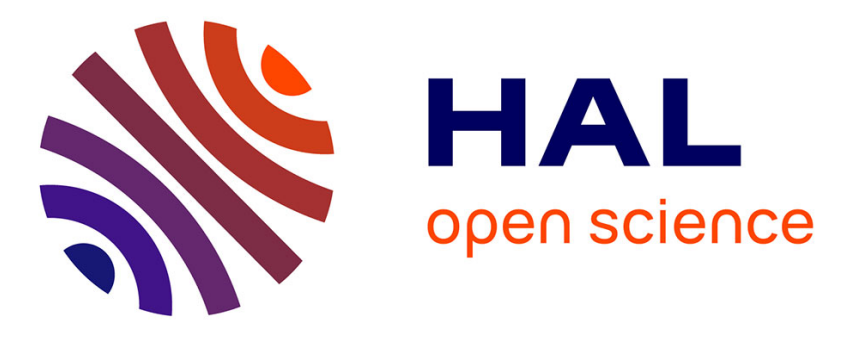

\title{
Subjective and physiological response to emotions in temporal lobe epilepsy and psychogenic non-epileptic seizures
}

\author{
Iliana Kotwas, Jean-Arthur Micoulaud-Franchi, Stephanie Khalfa, Aileen \\ Mcgonigal, Mireille Bastien-Toniazzo, Fabrice Bartolomei
}

\section{To cite this version:}

Iliana Kotwas, Jean-Arthur Micoulaud-Franchi, Stephanie Khalfa, Aileen Mcgonigal, Mireille BastienToniazzo, et al.. Subjective and physiological response to emotions in temporal lobe epilepsy and psychogenic non-epileptic seizures. Journal of Affective Disorders, 2019, 244, pp.46-53. 10.1016/j.jad.2018.10.004 . hal-02142541

\section{HAL Id: hal-02142541 \\ https://hal.science/hal-02142541}

Submitted on 28 May 2019

HAL is a multi-disciplinary open access archive for the deposit and dissemination of scientific research documents, whether they are published or not. The documents may come from teaching and research institutions in France or abroad, or from public or private research centers.
L'archive ouverte pluridisciplinaire HAL, est destinée au dépôt et à la diffusion de documents scientifiques de niveau recherche, publiés ou non, émanant des établissements d'enseignement et de recherche français ou étrangers, des laboratoires publics ou privés. 


\section{Accepted Manuscript}

Subjective and physiological response to emotions in temporal lobe epilepsy and psychogenic non-epileptic seizures

Iliana Kotwas, Jean-Arthur Micoulaud-Franchi, Stéphanie Khalfa, Aileen McGonigal , Mireille Bastien-Toniazzo, Fabrice Bartolomei

PII: S0165-0327(18)31300-4

DOI: https://doi.org/10.1016/j.jad.2018.10.004

Reference: $\quad$ JAD 10165

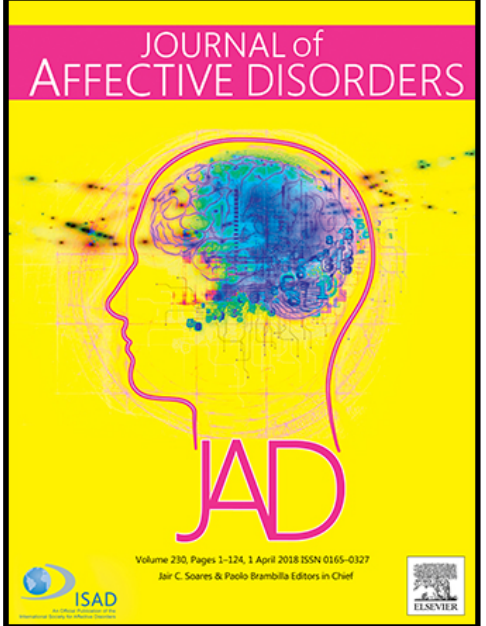

To appear in:

Journal of Affective Disorders

Please cite this article as: Iliana Kotwas, Jean-Arthur Micoulaud-Franchi, Stéphanie Khalfa, Aileen McGonigal, Mireille Bastien-Toniazzo, Fabrice Bartolomei, Subjective and physiological response to emotions in temporal lobe epilepsy and psychogenic non-epileptic seizures, Journal of Affective Disorders (2018), doi: https://doi.org/10.1016/j.jad.2018.10.004

This is a PDF file of an unedited manuscript that has been accepted for publication. As a service to our customers we are providing this early version of the manuscript. The manuscript will undergo copyediting, typesetting, and review of the resulting proof before it is published in its final form. Please note that during the production process errors may be discovered which could affect the content, and all legal disclaimers that apply to the journal pertain. 


\section{Highlights}

- TLE and PNES patients have increased risk of comorbid affective disorders

- Patients with these conditions disclose globally lower SCR to emotions than controls

- Differences with the controls are mainly observed in suppression condition

- Therapeutic methods targeting autonomic responses can be of interest for TLE and PNES 
Subjective and physiological response to emotions in temporal lobe epilepsy and psychogenic non-epileptic seizures

Running head : Electrodermal responses in TLE and PNES

Iliana Kotwas ${ }^{\mathrm{a},{ }^{*}}$, Jean-Arthur Micoulaud-Franchi ${ }^{\mathrm{b}, \mathrm{c}}$, Stéphanie Khalfa ${ }^{\mathrm{d}, \mathrm{e}}$, Aileen McGonigal ${ }^{\mathrm{f}, \mathrm{g}}$, Mireille Bastien-Toniazzo ${ }^{\text {a }}$ Fabrice Bartolomei ${ }^{\text {f, g }}$

a - Laboratoire Parole et Langage UMR 7309, Aix-Marseille Université, Marseille, France.

b - Service d'explorations fonctionnelles du système nerveux, Clinique du sommeil, CHU de Bordeaux, Place Amélie Raba-Léon, 33076 Bordeaux, France.

c - USR CNRS 3413 SANPSY, CHU Pellegrin, Université de Bordeaux, France.

d - National Center for Scientific Research (CNRS), Tímone Neuroscience Institute (INT, UMR 7289), Marseille, France.

e - Department of Neurosciences, Faculty of Life and Health Sciences, Aix-Marseille Université, Marseille, France.

f - Service de Neurophysiologie Clinique, Centre Hospitalo Universitaire de la Timone, 264, rue Saint-Pierre, 13005 Marseille, France.

g - Aix Marseille Univ, Inserm, INS, Institut de Neurosciences des Systèmes, Marseille, France

* Corresponding author at: Laboratoire Parole et Langage UMR 7309, Aix-Marseille Université, Marseille, France - email : $\underline{\text { iliana.kotwas@gmail.com }}$ 


\begin{abstract}
Background: Temporal lobe epilepsy (TLE) and psychogenic non-epileptic seizures (PNES) are conditions frequently associated with dysfunction in emotional regulation leading to increased risk of affective disorders. This study investigates emotional processing with an objective measure of emotional reactivity in patients with TLE and patients with PNES.

Methods: 34 patients with TLE and 14 patients with PNES were evaluated on skin conductance responses (SCR) to emotions induced by short films and compared to 34 healthy controls. An attention and a suppression condition were performed while viewing the films.

Results: The both groups of patients disclosed lower SCR to emotions compared to controls, mainly in suppression condition. While TLE patients had fower SCR in attention condition than controls for fear, sadness and happiness, PNES had lower SCR only for happiness. In suppression condition, both had lower SCR than controls except for peacefulness in both groups and sadness in PNES. Subjective evaluations revealed that both patient's groups scored a higher intensity for sadness than controls in attention and lower for in fear and disgust in suppression only in TLE.
\end{abstract}

Limitations: The sample size in the PNES group and the lack of a control group with similar levels of mood symptoms limited the interpretation of our results.

Conclusion: As no correlation were found between SCR to emotions and scores of affective disorders, this pattern of responses might be underpinned by specific pathophysiological and cognitive mechanisms related to TLE and to PNES. Thus, therapeutic approaches targeting emotional autonomic responses can be of interest in the management of these conditions.

\title{
Keywords
}

Temporal lobe epilepsy, psychogenic non-epileptic seizures, emotional regulation, skin conductance responses, psychiatric comorbidities. 


\section{Introduction}

In both epilepsy and psychogenic non-epileptic seizures (PNES) there is a high prevalence of comorbid mood disorders which are often described as the main factor contributing to poorer quality of life (Garcia, Garcia-Morales, \& Gil-Nagel, 2015; Szaflarski et al., 2003). PNES are involuntary episodes of alteration of consciousness and disturbance of sensory, motor, autonomic or cognitive functions that can be misdiagnosed as epileptic seizures. They are not caused by abnormal electrical discharges in the brain and are thought to be mainly triggered by emotional distress (Brown, Syed, Benbadis, LaFrance, \& Reuber, 2011). Although epilepsy and PNES are different medical conditions, similar psyehiatric comorbidity occurs in both.

Depressive disorders and anxiety disorders are the most psychiatric comorbidity frequently associated with epilepsy (Brandt et al., 2010; Gilliam et al., 2004), especially in drug-resistant patients, and have been demonstrated to be main factors contributing to poorer quality of life (Kanner, Barry, Gilliam, Hermann, \& Meador, 2010; Luoni et al., 2011). This has been attributed to different causes, such as a psychological reaction to a chronic disease, to the unpredictability of seizures and to the restriction of activities resulting in low self-esteem, to stigma and social rejection (Boylan et al., 2004; Vazquez \& Devinsky, 2003); but also to pathophysiological/mechanisms common to epilepsy and depressive and anxiety disorders, which are stress-related comorbidities (Maguire \& Salpekar, 2013). In patients with PNES, comorbid depressive and anxiety symptoms are also a main factor of decreased quality of life (Myers, Lancman, Laban-Grant, Matzner, \& Lancman, 2012; O’Brien et al., 2015; Rawlings, Brown, \& Reuber, 2017). Depressive and anxiety disorders are known to be underpinned by dysregulation of emotions (Campbell-Sills \& Barlow, 2007; Davidson, 2000). Wellbeing and satisfying social interactions are underpinned by appropriate emotional expression, requiring 
adequate emotional regulation strategies (Gross, 2002). From a cognitive point of view, emotional dysregulation is characterized by modified attentional processing toward emotional stimuli and difficulties in control of emotional expression. In depressive disorders, attention is automatically captured by depressive-related stimuli (Gotlib, Krasnoperova, Yue, \& Joormann, 2004), and in anxiety disorders by threatening stimuli (Bar-Haim, Lamy, Pergamin, Bakermans-Kranenburg, \& van Ijzendoorn, 2007). These cognitive biases are associated with deficits in cognitive control and may affect responses in emotional situations by altering relevant emotion regulation (Joormann \& Quinn, 2014). In patients with temporal lobe epilepsy (TLE) an attentional bias toward threatening stimuli has also been described (Bourgeat et al., 2011; Lanteaume, Bartolomei, \& Bastien-Toniazzo, 2009; Lanteaume et al., 2012), whereby these biases were expressed as vigilance or difficulty in disengaging attention from the stimulus in patients reporting stress as a seizure-triggering factor. However, in patients who did not report stress as a triggering factor for epileptic seizures, bias was expressed rather as an avoidance strategy In PNES, a vigilance bias toward threat has been shown, which was positively correlated to basal cortisol levels (Bakvis, Spinhoven, \& Roelofs, 2009). Slower approach behaviours to angry faces than healthy controls were also demonstrated (Bakvis, Spinhoven, Zitman, \& Roelofs, 2011), arguing for the presence of an avoidance bias in these patients. While precise features of these biases are not yet clearly understood, impairment in emotional processing in PNES is well established (Brown \& Reuber, 2016; Roberts \& Reuber, 2014).

The goal of this study is to investigate emotional processing with an objective measure of emotional reactivity in patients with TLE and patients with PNES. Skin conductance response (SCR) is used since it has been identified to be a measure of peripheral sympathetic autonomic nervous system activity, and to assess arousal and non-conscious responses to emotional stimuli (Grapperon, Pignol, \& Vion-Dury, 2012; Klorman, Wiesknleld, \& Austin, 
1975; Levenson, 2006). The groups of patients are compared to healthy controls in a condition of voluntary attention to emotional feeling, and in a condition of voluntary suppression of emotional expression using short film sequences inducing different emotions: fear, disgust, sadness, peacefulness and happiness. We hypothesized that more intense SCR and subjective evaluations for negative emotions, and less intense responses to positive emotions, would occur in TLE and PNES patients compared to healthy controls in an attending condition. Indeed, a physiological hyperactivity in TLE as well as in PNES could support the emotional vulnerability toward negative stimuli in both groups of patients. We also hypothesized less SCR to fear induction in a suppression condition in TLE and PNES patients compared to controls, which would indicate poorer control in patients.

\section{Methods and material}

\subsection{Participants}

Thirty-four patients with TLE and fourteen patients with PNES were recruited for the study in the Clinical Neurophysiology Department of the Marseille University Hospital (France). Inclusion criteria for TLE patients were as follows: EEG-verified diagnosis of TLE, drugresistant epilepsy (failure to control seizures despite adequate trials of at least 2 anti-epileptic drugs), duration of epilepsy more than 3 years. For patients with PNES we used the following criteria: diagnosed by video/EEG without ictal EEG discharge during the events and clinical interview (LaFrande, Baker, Duncan, Goldstein, \& Reuber, 2013). None of the patients in both groups had comorbidity other than depressive and anxiety disorders, notably no peripheral nervous system disorder that might affect SCR. However, two patients in the PNES group had a history of previous epilepsy, but whose seizures are currently well-controlled. Thirty-four healthy volunteers, with no history of neurological or psychiatric impairments were recruited as controls. All participants were aged between 18 and 65 years (Table 1). All 
participants received detailed information and gave written informed consent for the present research.

\subsection{Clinical evaluations}

\subsubsection{Beck Depression Inventory (BDI)}

The Beck Depression Inventory (BDI) (Beck, Ward, Mendelson, Mock, \& Erbaugh, 1961) is a self-assessment instrument designed to assess the presence and the severity of current (past 2 weeks) depressive symptoms. It consists in a 21-item scale in which the sum scores are ranged from 0 to 63 . The higher the score, the more severe the symptoms are. Each item is assessed from 0 to 3 to indicate the degree of the severity of the symptom screened. BDI is widely used for screening depression in epilepsy in clinical practice (de Oliveira et al., 2014; Micoulaud-Franchi, Bartolomei, Duncan, \& McGonigal, 2017). A cutoff point at 16 (>16) has been found to be the best performance score for screening depression in patients with epilepsy (de Oliveira et al., 2011).

\subsubsection{State-Trait Anxiety Inventory (STAI)}

Anxiety symptoms were measured by the State-Trait Anxiety Inventory (STAI) (Spielberger \& Vagg, 1984). This self-reported measure is composed in two parts in order to evaluate state anxiety and trait anxiety. State anxiety refers to a transitory emotional state that varies in intensity and fluctuates over time. Trait anxiety is a stable susceptibility to feel stress and worry and may be considered as a personality trait. It is a 20-item scale in which each item is scored with a 4-point Likert scale from "not at all" to "very much so" according to the degree of the symptoms. The total score ranges from 20 to 80 ; the higher the score, the more severe the anxiety condition. A total score of 40 or more indicates an anxious condition.

\subsection{Evaluation of emotional regulation}


The material and procedure were those used by (Reynaud, El-Khoury-Malhame, Blin, \& Khalfa, 2012). This task consisted in presenting 5 films inducing emotional responses (fear, disgust, sadness, peacefulness and happiness). Each sequence lasted $45 \mathrm{sec}$. For inducing happiness the sequence was an excerpt of the French movie "Le Dîner de Cons" by Weber ; for inducing sadness the sequence was extracted from a report on the famine in Biafra by National Audiovisual Institute ; for inducing fear the sequence was an excerpt of "A Tale of Two Sisters" by Jee-Woon, which begins with suspense and ends with an intense burst ; for inducing disgust it was an excerpt of "Accro" by Mettling; and for inducing peacefulness an excerpt of "Marche of the Penguins" by Jacquet.

This task was divided into two parts: 1) Attention condition: participants were asked to be attentive to the emotions they felt when watching the movies and experiencing them. 2) Suppression condition: participants were asked to control the emotions felt by trying to remove any emotional response. No control strategies were suggested, in an attempt to reproduce the patient's real-life approach to emotional regulation. Each subject underwent both conditions. The 5 movie sequences were randomly presented in pseudo-randomized order, but the order remained the same for each participant on both conditions (attention and suppression). The order of presentation of attention and suppression conditions was randomly counterbalanced between the participants. Between each sequence, a one-minute break was used for completing a questionnaire aimed at identifying the emotion the participants felt and the intensity with which they felt the induced emotion. The identification of emotions was selected from a choice between fear, disgust, sadness, peacefulness, happiness or "other". The rate of intensity was self-evaluated on a scale from 0 (no emotional intensity) to 9 (very high emotional intensity).

The films were presented by a computer running E-Prime (Psychology Software Tools, Inc., Pittsburgh, PA) and physiological data were acquired by another computer running AcqKnowledge software (Biopac Systems, Inc., Goleta, CA). Physiological channels were recorded at a rate of $1,000 \mathrm{~Hz}$ in continuous mode using the Biopac MP30 system including amplifiers for skin conductance responses (SCR) collection. Only phasic responses of skin 
conductance were recorded with the amplifier in the AC position. The module amplifiers used were 100C. SCR was recorded using 5-mm inner diameter $\mathrm{Ag} / \mathrm{AgCl}$ electrodes filled with isotonic electrode paste. Electrodes were attached to the volar surface of the second phalanx of the second and third left fingers (Fowles et al., 1981). The mean amplitude of peaks of SCR were measured only during the 45 seconds' duration of each film. The number of peaks was manually counted. SCR was obtained by averaging peaks' amplitude for each film (Boucsein, 2012). SCR below $0.01 \mu \mathrm{S}$ was not considered. Artifact correction for SCR consisted of a visual inspection of respiration and subsequent exclusion of SCR that seemed to be influenced by deep breath.

\subsection{Statistical analyses}

We first compared the three groups in terms of demographic characteristics and psychoaffective scores using $\chi^{2}$ test for categorical variables and a Student t-test (TLE vs Controls; TLE vs PNES ; PNES vs Controls) for quantitative variables. The effects of task condition (attention vs suppression) and emotions on change on SCR and subjective intensity was estimated using a linear mixed effect with two fixed effects (Group: TLE vs. PNES vs. Controls; and Condition: attention vs. suppression). Within-subject time factor and betweensubject group factor were examined. A Mann-Whitney $U$ test was used to perform the comparisons according to laterality of seizures in the TLE group. For all the tests, the accepted significance level was $5 \%$. For all the tests, the accepted significance level was $5 \%$. Data analyses were performed using ' $R$ ' software.

\section{Results}

\subsection{Sample characteristics}

Mean age was 37.56 years $(\mathrm{SD}=10.82$, range [18-60] years old) for TLE group (20 women, 14 men) and 32.93 ( $\mathrm{SD}=12.88$, range [18-52] years old) for PNES group (11 women, 3 men) and 31.65 ( $\mathrm{SD}=10.59$, range [19-63] years old) for the control group (24 women, 12 men). The groups did not differ on age (TLE vs controls ( $\mathrm{t}[66]=0.896, \mathrm{p}=.375)$; TLE vs PNES 
$(\mathrm{t}[46]=-1.258, \mathrm{p}=.215) ;$ PNES vs controls $(\mathrm{t}[46]=0.378, \mathrm{p}=.707))$ nor gender $($ TLE vs controls $\left(\chi^{2}[1, \mathrm{n}=68]=1.03, \mathrm{p}=.310\right) ; \operatorname{TLE}$ vs PNES $\left(\chi^{2}[1, \mathrm{n}=48]=1.691, \mathrm{p}=.194\right) ;$ PNES vs controls $(\chi 2[1, \mathrm{n}=48]=0.320, \mathrm{p}=.572))$. Statistical analyses reveal that the psychiatric comorbidity scores were significantly higher in TLE than controls: BDI (t[66] = $6.869, \mathrm{p}<.001) ;$ STAI-A $(\mathrm{t}[66]=-4.268, \mathrm{p}<.001) ;$ STAI-B $(\mathrm{t}[66]=-3.652, \mathrm{p}<.001)$. TLE and PNES were not different on scores for BDI $(\mathrm{t}[46]=0.896, \mathrm{p}=.375)$; on STAI-A $(\mathrm{t}[46]=$ 1.275, $\mathrm{p}=.209) ;$ and STAI-B $(\mathrm{t}[46]=-0.033, \mathrm{p}=.974)$. PNES and controls were different on BDI $(\mathrm{t}[46]=9.167, \mathrm{p}<.001) \quad ;$ STAI-A $(\mathrm{t}[46]=5.601, \mathrm{p}<.001) ;$ STAI-B $(\mathrm{t}[46]=3.117$, p=.003) (table 2). Concerning BDI, 13/34 TLE patient and 7/15 PNES patients scored higher than the cut-off (16) indicating a possible depression, although none of the control group did.

\subsection{Subjective evaluation of emotional intensity (Fig.1)}

In the TLE group the intensity evaluation was significantly higher in attention than suppression condition for all emotions : Fear (estimate: -2.058 , standard error: 0.435 , t value: -4.731, $\mathrm{p}$ value<.0001), Disgust (estimate: -2.753 , standard error: $0.365, \mathrm{t}$ value: $-7.3674, \mathrm{p}$ value<.0001), Sadness (estimate: -1.735 , standard error: 0.654, t value: $-4.758, \mathrm{p}$ value<.0001), peacefulness (estimate: -1.058 , standard error: $0.453, \mathrm{t}$ value: $-2.336, \mathrm{p}$ value: .02 ), happiness (estimate: -1.5 , standard error: 0.439 , t value: -3.411 , $\mathrm{p}$ value: .001 ). In PNES group the intensity was scored significantly higher in attention condition for Disgust (estimate: -1.785 , standard error: 0.555, t value: -3.215 , p value: .002), Sadness (estimate: 1.357, standard error: 0.568, $\mathrm{t}$ value: -2.388 , $\mathrm{p}$ value: .02) and Peacefulness (estimate: -2.071 , standard error: 0.706 , t value: -2.932 , p value.004). In control group the intensity scores were significantly higher in attention condition for Disgust (estimate: -1.03 , standard error: $0.36, \mathrm{t}$ value: -2.858, p value: .005) and Peacefulness (estimate: -1.196 , standard error: $0.457, \mathrm{t}$ value: -2.613, p value: .01) only. 
Comparisons between TLE and control groups reveal that TLE scored lower than controls in suppression condition for Fear and Disgust but not in attention condition. On the contrary, they scored higher than controls in attention but not in suppression condition for Sadness. PNES group differed only with controls on Sadness with higher scores on attention condition (see Supplementary tables).

In summary, the TLE patients scored the intensity lower when they were asked to suppress their own emotional responses than when they were asked to pay attention to the emotion they felt. This was less clear in PNES and controls, but they appeared to tend to have a similar pattern, at least for some emotions. However, the groups did not show many differences between each other, only between TLE and controls with an intensity scored higher in attention condition for Sadness and lower in Fear and Disgust in suppression in TLE compared to controls, and between PNES and controls with higher scores for Sadness in attention condition for PNES

\subsection{Electrodermal responses to emotions (Fig.2)}

In the control group SCR was significantly greater in suppression than attention condition for Fear (estimate: 0.425 , standard error: 0.112 , t value: $3.792, \mathrm{p}$ value: .0002) and significantly greater in attention than suppression condition for Happiness (estimate: -0.15 standard error: 0.065, t value: $-2.322, p$ value: .02). In TLE and PNES groups, SCR did not differ between the task conditions in any of the five emotions.

Comparisons between TLE and controls revealed that group SCR was significantly lower in TLE than controls in the attention condition for Fear, Sadness and Happiness; and in the suppression condition for Fear, Disgust, Sadness and Happiness. Comparisons between PNES and controls revealed that group SCR was significantly lower in PNES than controls in the attention condition for Happiness only; and in the suppression condition for Fear, Sadness and 
Happiness. TLE and PNES did not differ on any conditions for any emotions (see Supplementary tables).

Thus, in summary, TLE patients disclosed a very different pattern of SCR to emotions compared to controls. The results were not significantly different only for Disgust in attention condition and Peacefulness in both conditions. PNES patients disclosed a trend of lower responses, but it was only significant for Happiness in both conditions and for Fear and Sadness in the suppression condition.

\subsection{Correlation between scores of depression and anxiety and electrodermal responses}

No correlations were found between scores at BDI and STAI and electrodermal responses in any of the five emotions in both conditions in TLE and PNES group. In control group a negative correlation was found between BDI scores and electrodermal responses to Happiness in attention condition $(\mathrm{r}(33)=-0.360, \mathrm{P}=.018)$,

\subsection{Effect of epilepsy laterality}

The TLE group was composed of 19 patients with left-sided TLE, 11 with right-sided and 4 with bilateral TLE. Due to small sample size, the 4 bilateral TLE were not included in the laterality analysis. Comparisons between left-sided and right-sided TLE patients revealed no significant differences for intensity rating or for SCR in any of the five emotions in the two task conditions.

\section{Discussion}

The goal of this study was to compare physiological changes and subjective evaluations in responses to emotional induction between TLE patients, PNES patients and healthy controls. The main result concerning physiological changes is that the groups disclosed different patterns of SCR to emotions. Globally, TLE and PNES patients showed no differences between the two task conditions whereas the control group had greater responses for fear in 
the suppression condition and for happiness in the attention condition. This pattern of results in controls has already been described since emotional suppression for fear (Reynaud et al., 2012) and disgust (Gross, 1998a; Gross \& Levenson, 1993) increased SCR because the autonomic sympathetic nervous system is involved in the preparation of intellectual activity and tasks demanding attention (Critchley, 2002). SCR are also increased by experiencing pleasant emotions and are mostly related to the arousal of the emotion (Bernat, Patrick, Benning, \& Tellegen, 2006; Bradley, Codispoti, Cuthbert, \& Lang, 2001); this could explain why SCR are greater for happiness when the participants are asked to pay attention to their emotions and to experience them fully. TLE patients and controls showed different SCR to most of the emotions in both conditions. This difference was less clear between patients with PNES and controls, but PNES patients also tended to disclose smaller responses than controls. On subjective evaluations, the three groups did not globally score differently between each other. However, in each group participants tended to attribute smaller scores of intensity in the suppression condition, mostly in the TLE group which scored all emotions as less intense in the suppression than in the attention condition, although the PNES group did so only for disgust, sadness and peacefulness, and the control group for disgust and sadness. Moreover, the TLE group perceived fear and disgust as being less intense than controls did in the suppression condition, indicating that their self-perception of emotional suppression is higher. Impairment in identifying emotions is well-known in TLE, particularly for identification of emotional facial expression (Amlerova et al., 2014; Bonora et al., 2011; Hlobil, Rathore, Alexander, Sarma, \& Radhakrishnan, 2008; Labudda, Mertens, Steinkroeger, Bien, \& Woermann, 2014; Meletti et al., 2003; Stefano Meletti et al., 2009; Yamada et al., 2005). A study shown that emotion recognition of facial emotions depends mainly on mesial temporal structures, particularly the amygdala (Anderson, Spencer, Fulbright, \& Phelps, 2000). Findings in patients with mesial TLE showed that this involvement could be hemisphere- 
dependent (Bonora et al., 2011; Stefano Meletti et al., 2009), but other data did not find any differences according to epilepsy lateralization (Amlerova et al., 2014). The results in the present study are in line with Amlerova et al. (2014) findings, since there were no differences between left-sided and right-sided TLE patients in emotional intensity ratings, or for SCR to emotions. However, our sample was relatively small, so the conclusion must be taken with caution. Hemispheric lateralization in emotional processing remains a topic of debate. The asymmetric hypothesis suggests that each hemisphere is specialized in the processing of emotions according to their valence (positive emotions for right hemisphere and negative ones for left hemisphere) (Davidson, 1992; Davidson, Ekman, Saron, Senulis, \& Friesen, 1990). Other findings suggest a dominance of right hemisphere for the processing of all kinds of emotions (Gainotti, 2018), although other studies found an advantage of right hemisphere only for conscious, but not unconscious, perception of negative emotion, but not for positive ones (Smith \& Bulman-Fleming, 2005). Nevertheless, these theories are not mutually exclusive in the processing of facial emotional expression (Prete, Capotosto, Zappasodi, \& Tommasi, 2018) and the role played by the temporal lobe would be dependent on both hemispheres (Killgore \& Yurgelun-Todd, 2007).

The two most studied strategies are the suppression of emotional expression, and cognitive reappraisal (Gross \& John, 2003). Both strategies focused on emotional responses and aim to hide the behavioral components of the response for suppression, and to reevaluate an emotional event to reduce its impact. In healthy subjects, it has been described that suppression does not modify the subjective experience of emotion but induces activation of autonomic responses, whereas reappraisal decreases subjective experience without any change in autonomic responses (Gross, 1998b). In the present study, the two groups of patients scored significantly lower in the suppression condition than the attention condition in several emotions, and no changes were observed on SCR. These results could argue for the 
use of a reappraisal strategy more than suppression of emotional expression. On the other hand, no instructions about emotional strategy were given for the suppression condition, and subjects were told only to suppress emotional reactions, so it was not possible to know what kind of emotional regulation strategies were used by the participants. It has previously been shown that patients with PNES tend to use more suppression and less reappraisal strategies than healthy controls (Gul \& Ahmad, 2014). Patients with epilepsy tend to use more often strategies focusing on emotions and particularly disengagement strategies consisting mainly in denial, avoidance or distraction from the source of the negative emotion than healthy controls (Oosterhuis, 1999).

These results show that the processes of emotion suppression could be modified by TLE and by PNES. The fact of having lower SCR than controls but verbal assessment equal to controls in attention condition in TLE patients suggests a dissociation between their subjective experience of emotions and their physiological responses to them. These results suggest that TLE patients subjectively experience emotions (except sadness) in the same way as controls in the attention condition, but that they disclose dysfunctions in physiological responses. These physiological dysfunctions could also be related to their associated anxious and depressive comorbidity. However, Rudolf Hoehn-Saric \& McLeod (2000) found that patients with anxiety disorder exhibited reduced physiological reactivity (heart rate, skin conductance, electromyography) when exposed to stressful stimuli compared to control subjects. In depression, data remain unclear, but most of the studies tend to converge to lower overall SCR than in controls without depressive disorder (Sarchiapone et al., 2018). A similar pattern of results has been observed in studies with emotional induction by reading emotional eliciting stories (Branković, 2008) or viewing affective pictures (Mardaga \& Hansenne, 2009). On the other hand, increased SCR have also been observed in depressed patients in responses to affective video-clips compared to neutral ones and to healthy controls (Schneider 
et al., 2012). Thus, heterogeneity of results and study designs do not allow clear conclusions to be drawn, and it cannot be presumed that the results observed in TLE patients here are clearly related to associated depressive and anxiety disorders. Indeed, no correlations were found between scores of depression and anxiety and SCR to emotions in TLE and PNES, and both groups did not disclose exactly the same pattern of SCR although they were equal on depression and anxiety scores.

It is possible that the observed hypoactivity compared to healthy controls is related to specific mechanisms involved in these conditions. Dysfunctions and changes in autonomic nervous system have been shown in epilepsy and considered related to risk of Sudden Unexpected Death in Epilepsy (SUDEP) (Devinsky, 2004; Evrengül et al., 2005; Sevcencu \& Struijk, 2010). These alterations are not only related to seizures themselves since they also exist during interictal periods (Devinsky, Perrine, \& Theodore, 1994), and are more evident in drug-resistant TLE (Ansakorpi et al., 2000). These studies focused on cardiovascular autonomic activity, but others were also conducted on SCR. Poh et al. (2012) investigated autonomic functioning during ictal and postictal periods and demonstrated increase in electrodermal activity during complex partial seizures and generalized tonic-clonic seizures (Poh et al., 2012); increase in electrodermal activity also correlated with the increase in the duration of EEG suppression in postictal period. However, an inverse relationship has been observed between SCR and cortical excitability. Indeed, Nagai, Goldstein, Critchley, \& Fenwick (2004) demonstrated that sympathetic nervous activity, measured by SCR, decreases when cortical excitation increases, and conversely it increases when cortical excitation decreases in healthy participants as well as in patients with epilepsy (Nagai, Critchley, Rothwell, Duncan, \& Trimble, 2009). This observation could be a possible explanation of why patients with TLE disclose reduced SCR to emotions compared to controls. However, in the present study, TLE and control groups did not differ on SCR to peacefulness, which can 
be considered as an emotional baseline, meaning that the pattern of SCR observed in TLE is mainly related to physiological emotional dysregulation rather than a global dysfunction of the autonomic sympathetic nervous system.

Emotional processing using attentional mechanisms has been shown in TLE. Indeed, an attentional bias toward threatening stimuli has been described (Bourgeat et al., 2011; Lanteaume et al., 2009). However, the attentional biases in TLE appear to depend on stress vulnerability as a seizure trigger. Patients with stress sensitivity disclose a disengaging problem to threatening stimuli, whereas those without stress sensitivity disclose avoiding behaviour to those stimuli. The attentional bias was correlated with hypometabolism in the anterior temporal lobe, including amygdala and hippocampus, in patients with stress-triggered seizures, but not in the non-stress-triggered ones (Lanteaume et al., 2012). This neurocognitive pattern may underlie seizure stress sensitivity but not depressive or anxiety disorders comorbid to epilepsy, because the two groups did not differ on depressive and anxiety scales scores. These results argue for specific processing of negative emotional information in the early stages of attentional processing in patients with epilepsy. However, in a group of patients with comorbid negative affect evaluated by the Beck Depression Inventory (Beck et al., 1961), an event-related potential study showed impairment during later stages of emotional regulation processing but not in early stages involving attentional processing (De Taeye et al., 2015). Studies are not all in agreement with regards to differences in emotional processing between patients with epilepsy and controls; some reports found differences only for neural stimuli but not emotional ones. Concerning the valence of emotions, (Banks, Bellerose, Douglas, \& Jones-Gotman, 2014) found no differences for emotional faces, but neutral faces were less accurately recognized by patients with epilepsy. In another study, the judgment of the intensity and the arousal were also different for neutral stimuli which are 
judged with higher intensity (Bourgeat et al., 2011) and higher arousal (Hennion et al., 2015) by patients with epilepsy than controls, but not for positive and negative ones.

\section{Limitations}

A main limitation of the study is the sample size in the PNES group, and the lack of a control group with similar levels of mood symptoms to allow interpretation as to whether the psychophysiological results derive from internalizing disorders more generally, or from epilepsy or PNES more specifically. Future research would benefit from comparisons with patients with depressive and anxiety disorders in an attempt to evaluate if specific psychiatric diagnoses may directly explain the physiological responses to emotions. Another limitation of these results is that antiepileptic drugs as well as antidepressant drugs can influence autonomic nervous system activity and most of the patients were on medication. Indeed, some anti-epileptic drugs can cause increased sympathetic activity during sleep (Hennessy, Tighe, Binnie, \& Nashef, 2001), arrhythmias or elevations of body temperature or (Devinsky et al., 1994). Results investigating electrodermal activity and antidepressants have shown mixed results: some found no correlations between them, whereas others found reduction in electrodermal activity in subjects taking medications (Sarchiapone et al., 2018). Otherwise, dissociative symptoms can also influence the autonomic nervous system (Pick, Mellers, \& Goldstein, s. d.; Schäflein, Sattel, Schmidt, \& Sack, 2018), and are known to be frequently associated with PNES (Reuber et al., 2011; Roberts \& Reuber, 2014). Dissociative symptoms were not evaluated in the present study, but should be considered in future studies. Another limitation lies in the gender diversity in the groups. All three groups are composed by a larger proportion of women, and gender differences could influence emotional responses and sensitivity to aversive information (Bale, 2006). Studies have shown differences in emotional recognition between women and men, in which women performed better in recognition of emotional prosody (Demenescu, Mathiak, \& Mathiak, 2014; Lambrecht, Kreifelts, \& Wildgruber, 2014) and of emotional facial expressions (Saylik, Raman, \& Szameitat, 2018). However, a recent study found a difference limited to facial expression of disgust recognized more accurately by women (Connolly, Lefevre, Young, \& Lewis, 2018). The groups in the present study are not statistically different in terms of gender, but they are too small to 
evaluate the differences between gender in each one, especially in PNES group. Further study should investigate whether gender differences in subjective evaluations and SCR to emotions exist in TLE patients and PNES patients.

\section{Conclusion}

To date, little is known about physiological responses to emotions in patients with TLE and patients with PNES. Our data showed differences in SCR to several emotions in these both groups of patients with global physiological hypoactivity, especially in TLE compared to healthy controls. Further studies are needed to better understand emotional processing and regulation in these patients, in order to better orientate therapeutic approaches to the frequently associated psychiatric comorbidity. Management by SCR biofeedback has already shown some efficacy on these comorbidities in patients with TLE and stress-sensitivity (Micoulaud-Franchi et al., 2014). Insofar as this approach aims to increase skin conductance over sessions in order to reduce the seizure onset, this increase could also underlie its efficacy on depressive and anxiety disorders. Thus, studies are needed to investigate how physiological responses can be modified by various therapeutic methods and if they are related to clinical improvement in patients with epilepsy as well as in patients with PNES.

\section{Acknowledgement}

None

\section{Fundings}

This study was supported by the Fondation Française pour la Recherche contre l'Epilepsie (FFRE). Research supported by grants ANR-16-CONV-0002 (ILCB), ANR-11-LABX-0036 (BLRI) and the Excellence Initiative of Aix-Marseille University (A*MIDEX). 
Amlerova, J., Cavanna, A. E., Bradac, O., Javurkova, A., Raudenska, J., \& Marusic, P. (2014). Emotion recognition and social cognition in temporal lobe epilepsy and the effect of epilepsy surgery. Epilepsy \& Behavior, 36, 86-89. https://doi.org/10.1016/j.yebeh.2014.05.001

Anderson, A. K., Spencer, D. D., Fulbright, R. K., \& Phelps, E. A. (2000). Contribution of the anteromedial temporal lobes to the evaluation of facial emotion. Neuropsychology, 14(4), 526- 536. https://doi.org/10.1037/0894-4105.14.4.526

Ansakorpi, H., Korpelainen, J. T., Suominen, K., Tolonen, U., Myllylä, V. V., \& Isojärvi, J. I. (2000). Interictal cardiovascular autonomic responses in patients with temporal lobe epilepsy. Epilepsia, 41(1), 42- 47.

https://doi.org/10.1111/j.15281157.2000.tb01503.x

Bakvis, P., Spinhoven, P., \& Roelofs, K. (2009). Basal cortisol is positively correlated to threat vigilance in patients with psychogenic nonepileptic seizures. Epilepsy \& Behavior, 16(3), 558- 560. https://doi.org/10.1016/j.yebeh.2009.09.006

Bakvis, P., Spinhoven, P., Zitman, F. G., \& Roelofs, K. (2011). Automatic avoidance tendencies in patients with psychogenic non-epileptic seizures. Seizure, 20(8), 628- 634. https://doi.org/10.1016/j.seizure.2011.06.006

Bale, T. L. (2006). Stress sensitivity and the development of affective disorders. Hormones and Behavior, 50(4), 529- 533. https://doi.org/10.1016/j.yhbeh.2006.06.033

Banks, S. J., Bellerose, J., Douglas, D., \& Jones-Gotman, M. (2014). The Insular Cortex: Relationship to Skin Conductance Responses to Facial Expression of Emotion in Temporal Lobe Epilepsy. Applied Psychophysiology and Biofeedback, 39(1), 1- 8. https://doi.org/10.1007/s10484-013-9236-3 
Bar-Haim, Y., Lamy, D., Pergamin, L., Bakermans-Kranenburg, M. J., \& van Ijzendoorn, M. H. (2007). Threat-Related Attentional Bias in Anxious and Nonanxious Individuals: A Meta-Analytic Study. Psychological Bulletin, 133(1), 1- 24.

Beck, A. T., Ward, C. H., Mendelson, M., Mock, J., \& Erbaugh, J. (1961). An inventory for measuring depression. Archives of General Psychiatry, 4, 561- 571.

Bernat, E., Patrick, C., Benning, S. D., \& Tellegen, A. (2006). Effects of picture content and intensity on affective physiological response. Psychophysiology, 43(1), 93- 103. https://doi.org/10.1111/j.1469-8986.2006.00380.x

Bonora, A., Benuzzi, F., Monti, G., Mirandola, L., Pugnaghi, M., Nichelli, P., \& Meletti, S. (2011). Recognition of emotions from faces and voices in medial temporal lobe epilepsy. Epilepsy \& Behavior, 20(4), 648-654. https://doi.org/10.1016/j.yebeh.2011.01.027

Boucsein, W. (2012). Electrodermal activity.Springer Science \& Business Media.

Bourgeat, F., Borg, C., Bedoin, N., Convers, P., Billard, S., Royer, A., ... Thomas-Antérion, C. (2011). Explicit and implicit emotional processing modifications in pharmacoresistant left temporal lobe epilepsy and anxiodepressive disorders. Epilepsy \& Behavior, 21(4), 367-372. https://doi.org/10.1016/j.yebeh.2011.06.001

Boylan, L. S., Flint, L. A., Labovitz, D. L., Jackson, S. C., Starner, K., \& Devinsky, O. (2004). Depression but not seizure frequency predicts quality of life in treatmentresistant epilepsy. Neurology, 62(2), 258- 261.

Bradley, M. M., Codispoti, M., Cuthbert, B. N., \& Lang, P. J. (2001). Emotion and motivation I: Defensive and appetitive reactions in picture processing. Emotion, 1(3), 276- 298. https://doi.org/10.1037/1528-3542.1.3.276

Brandt, C., Schoendienst, M., Trentowska, M., May, T. W., Pohlmann-Eden, B., TuschenCaffier, B., ... Ebner, A. (2010). Prevalence of anxiety disorders in patients with 
refractory focal epilepsy-a prospective clinic based survey. Epilepsy \& Behavior, 17(2), 259- 263. https://doi.org/10.1016/j.yebeh.2009.12.009

Branković, S. B. (2008). System identification of skin conductance response in depression-an attempt to probe the neurochemistry of limbic system. Psychiatria Danubina, 20(3), $310-322$.

Brown, R. J., \& Reuber, M. (2016). Psychological and psychiatric aspects of psychogenic non-epileptic seizures (PNES): A systematic review. Clinical Psychology Review, 45, 157- 182. https://doi.org/10.1016/j.cpr.2016.01.003

Brown, R. J., Syed, T. U., Benbadis, S., LaFrance, W. C., \& Reuber, M. (2011). Psychogenic nonepileptic seizures. Epilepsy \& Behavior, 22(1), 85-93. https://doi.org/10.1016/j.yebeh.2011.02.016

Campbell-Sills, L., \& Barlow, D. (2007). Incorporating emotion regulation into conceptualizations and treatments of anxiety and mood disorders. In Handbook of Emotion Regulation (Gross JJ, p. 542-559). New-York: Guilford.

Connolly, H. L., Lefevre, C. E., Young, A. W., \& Lewis, G. J. (2018). Sex differences in emotion recognition: Evidence for a small overall female superiority on facial disgust. Emotion (Washington, D.C.). https://doi.org/10.1037/emo0000446

Critchley, H. D. (2002). Book review: electrodermal responses: what happens in the brain. The Neuroscientist, 8(2), 132-142.

Davidson, R. J. (2000). Affective style, psychopathology, and resilience: brain mechanisms and plasticity. The American Psychologist, 55(11), 1196- 1214.

Davidson, Richard J. (1992). Anterior Cerebral Asymmetry and the Nature of Emotion. Brain and Cognition, 20, 125- 151. 
Davidson, Richard J., Ekman, P., Saron, C. D., Senulis, J. A., \& Friesen, W. V. (1990). Approach-withdrawal and cerebral asymmetry: Emotional expression and brain physiology: I. Journal of personality and social psychology, 58(2), 330.

de Oliveira, G. N., Lessa, J. M. K., Gonçalves, A. P., Portela, E. J., Sander, J. W., \& Teixeira, A. L. (2014). Screening for depression in people with epilepsy: Comparative study among Neurological Disorders Depression Inventory for Epilepsy (NDDI-E), Hospital Anxiety and Depression Scale Depression Subscale (HADS-D), and Beck Depression Inventory (BDI). Epilepsy $\quad \& \quad$ Behavior, 24 34. 50-54. https://doi.org/10.1016/j.yebeh.2014.03.003

De Taeye, L., Pourtois, G., Meurs, A., Boon, P., Vonck, K., Carrette, E., \& Raedt, R. (2015). Event-Related Potentials Reveal Preserved Attention Allocation but Impaired Emotion Regulation in Patients with Epilepsy and Comorbid Negative Affect. PLOS ONE, 10(1), e0116817. https://doi.org/10.1371/journal.pone.0116817

Demenescu, L. R., Mathiak, K. A., \& Mathiak, K. (2014). Age- and gender-related variations of emotion recognition in pseudowords and faces. Experimental Aging Research, 40(2), 187- 207. https://doi.org/10.1080/0361073X.2014.882210

Devinsky, O. (2004). Effects of Seizures on Autonomic and Cardiovascular Function., Effects of Seizures on Autonomic and Cardiovascular Function. Epilepsy Currents, Epilepsy Currents, 4, 4(2, 2), 43, 43- 46. https://doi.org/10.1111/j.1535-7597.2004.42001.x, 10.1111/j.1535-7597.2004.42001.x

Devinsky, O., Perrine, K., \& Theodore, W. H. (1994). Interictal autonomic nervous system function in patients with epilepsy. Epilepsia, 35(1), 199- 204. https://doi.org/10.1111/j.1528-1157.1994.tb02933.x

Evrengül, H., Tanriverdi, H., Dursunoglu, D., Kaftan, A., Kuru, O., Unlu, U., \& Kilic, M. (2005). Time and frequency domain analyses of heart rate variability in patients with 
$\begin{array}{llll}\text { epilepsy. } & \text { Epilepsy } & \text { Research, } & \text { 63(2-3), }\end{array}$ https://doi.org/10.1016/j.eplepsyres.2005.02.001

Fowles, D. C., Christie, M. J., Edelberg, R., Grings, W. W., Lykken, D. T., \& Venables, P. H. (1981). Publication recommendations for electrodermal measurements. Psychophysiology, 18(3), 232-239.

Gainotti, G. (2018). Emotions and the Right Hemisphere: Can New Data Clarify Old Models? The Neuroscientist: A Review Journal Bringing Neurobiology, Neurology and Psychiatry, 1073858418785342. https://doi.org/10.1177/1073858418785342

Garcia, M. E., Garcia-Morales, I., \& Gil-Nagel, A. (2015). Prevalence of depressive symptoms and their impact on quality of life in patients with drug-resistant focal epilepsy (IMDYVA study). Epilepsy Research, 110, 157-165. https://doi.org/10.1016/j.eplepsyres.2014.11.003

Gilliam, F. G., Santos, J., Vahle, V., Carter, J., Brown, K., \& Hecimovic, H. (2004). Depression in epilepsy: ignoring clinical expression of neuronal network dysfunction? Epilepsia, 45(s2), 28-33.

Gotlib, I. H., Krasnoperova, E. Yue, D. N., \& Joormann, J. (2004). Attentional biases for negative interpersonal stimuli in clinical depression. Journal of abnormal psychology, 113(1), 127 .

Grapperon, J., Pignol, A.-C., \& Vion-Dury, J. (2012). La mesure de la réaction électrodermale. L'Encéphale, $\quad 38(2)$, $149-155$. https://doi.org/10.1016/j.encep.2011.05.004

Gross, J. J. (1998a). Antecedent- and response-focused emotion regulation: Divergent consequences for experience, expression, and physiology. Journal of Personality and Social Psychology, 74(1), 224- 237. https://doi.org/10.1037/0022-3514.74.1.224 
Gross, J. J. (1998b). The emerging field of emotion regulation: An integrative review. Review of General Psychology, 2(3), 271 - 299. https://doi.org/10.1037/1089-2680.2.3.271

Gross, J. J. (2002). Emotion regulation: Affective, cognitive, and social consequences. Psychophysiology, 39(3), 281-291.

Gross, J. J., \& John, O. P. (2003). Individual differences in two emotion regulation processes: Implications for affect, relationships, and well-being. Journal of Personality and Social Psychology, 85(2), 348- 362. https://doi.org/10.1037/0022-3514.85.2.348

Gross, J. J., \& Levenson, R. W. (1993). Emotional suppression: Physiology, self-report, and expressive behavior. Journal of Personality and Social Psychology, 64(6), 970- 986. https://doi.org/10.1037/0022-3514.64.6.970

Gul, A., \& Ahmad, H. (2014). Cognitive deficits and emotion regulation strategies in patients with psychogenic nonepileptic seizures: a task-switching study. Epilepsy \& Behavior: $E \& B, 32,108$ - 113. https://doi.org/10.1016/j.yebeh.2014.01.015

Hennessy, M. J., Tighe, M. G., Binnie, C. D., \& Nashef, L. (2001). Sudden withdrawal of carbamazepine increases cardiac sympathetic activity in sleep. Neurology, 57(9), $1650-1654$.

Hennion, S., Sequeira, H., D'Hondt, F., Duhamel, A., Lopes, R., Tyvaert, L., ... Delbeuck, X. (2015). Arousal in response to neutral pictures is modified in temporal lobe epilepsy. Epilepsy \& Behavior, 45, 15 - 20. https://doi.org/10.1016/j.yebeh.2015.02.005

Hlobil, U., Rathore, C., Alexander, A., Sarma, S., \& Radhakrishnan, K. (2008). Impaired facial emotion recognition in patients with mesial temporal lobe epilepsy associated with hippocampal sclerosis (MTLE-HS): Side and age at onset matters. Epilepsy Research, 80(2- 3), 150- 157. https://doi.org/10.1016/j.eplepsyres.2008.03.018

Hoehn-Saric, R., \& McLeod, D. R. (2000). Anxiety and arousal: physiological changes and their perception. Journal of affective disorders, 61(3), 217-224. 
Joormann, J., \& Quinn, M. E. (2014). COGNITIVE PROCESSES AND EMOTION REGULATION IN DEPRESSION: Review: Cognitive Processes in Depression. Depression and Anxiety, 31(4), 308- 315. https://doi.org/10.1002/da.22264

Kanner, A. M., Barry, J. J., Gilliam, F., Hermann, B., \& Meador, K. J. (2010). Anxiety disorders, subsyndromic depressive episodes, and major depressive episodes: Do they differ on their impact on the quality of life of patients with epilepsy? Epilepsia, 51(7), 1152- 1158. https://doi.org/10.1111/j.1528-1167.2010.02582.x

Killgore, W. D. S., \& Yurgelun-Todd, D. A. (2007). The right-hemisphere and valence hypotheses: could they both be right (and sometimes left)? Social cognitive and affective neuroscience, 2(3), 240- 250. https://doi.org/10.1093/scan/nsm020

Klorman, R., Wiesknleld, A. R., \& Austin, M. L. (1975). Autonomic responses to affective visual stimuli. Psychophysiology, 12(5), 553-560.

Labudda, K., Mertens, M., Steinkroeger, C., Bien, C. G., \& Woermann, F. G. (2014). Lesion side matters - An fMRI study on the association between neural correlates of watching dynamic fearful faces and their evaluation in patients with temporal lobe epilepsy. Epilepsy $\quad \& \quad$ Behavior, $31, \quad 321-328$. https://doi.org/10.1016/j.yebeh.2013.10.014

LaFrance, W. C., Baker, G. A., Duncan, R., Goldstein, L. H., \& Reuber, M. (2013). Minimum requirements for the diagnosis of psychogenic nonepileptic seizures: a staged approach: a report from the International League Against Epilepsy Nonepileptic Seizures Task Force. Epilepsia, 54(11), 2005- 2018. https://doi.org/10.1111/epi.12356

Lambrecht, L., Kreifelts, B., \& Wildgruber, D. (2014). Gender differences in emotion recognition: Impact of sensory modality and emotional category. Cognition \& Emotion, 28(3), 452- 469. https://doi.org/10.1080/02699931.2013.837378 
Lanteaume, L., Bartolomei, F., \& Bastien-Toniazzo, M. (2009). How do cognition, emotion, and epileptogenesis meet? A study of emotional cognitive bias in temporal lobe epilepsy. Epilepsy $\quad \& \quad$ Behavior, $\quad$ 15(2), 218 - 224. https://doi.org/10.1016/j.yebeh.2009.03.034

Lanteaume, L., Guedj, E., Bastien-Toniazzo, M., Magalahaes, A., Mundler, O., \& Bartolomei, F. (2012). Cognitive and metabolic correlates of emotional vulnerability in patients with temporal lobe epilepsy. Journal of Neurology, Neurosurgery \& Psychiatry, 83(5), $522-528$.

Levenson, R. W. (2006). Blood, Sweat, and Fears: The Autonomic Architecture of Emotion. Annals of the New York Academy of Sciences, 1000(1), 348-366. https://doi.org/10.1196/annals.1280.016

Luoni, C., Bisulli, F., Canevini, M. P., De Sarro, G., Fattore, C., Galimberti, C. A., ... on behalf of the SOPHIE Study Group. (2011). Determinants of health-related quality of life in pharmacoresistant epilepsy: Results from a large multicenter study of consecutively enrolled patients using validated quantitative assessments: Quality of Life in Pharmacoresistant Epilepsy. Epilepsia, 52(12), 2181-2191. https://doi.org/10.1111/j.1528-1167.2011.03325.x

Maguire, J., \& Salpekar, J. A. (2013). Stress, seizures, and hypothalamic-pituitary-adrenal axis targets for the treatment of epilepsy. Epilepsy \& Behavior, 26(3), 352- 362. https://doi.org/10.1016/j.yebeh.2012.09.040

Mardaga, S., \& Hansenne, M. (2009). Autonomic aspect of emotional response in depressed patients: relationships with personality. Neurophysiologie Clinique $=$ Clinical Neurophysiology, 39(4- 5), 209- 216. https://doi.org/10.1016/j.neucli.2009.06.002 
Meletti, S., Benuzzi, F., Rubboli, G., Cantalupo, G., Stanzani Maserati, M., Nichelli, P., \& Tassinari, C. A. (2003). Impaired facial emotion recognition in early-onset right mesial temporal lobe epilepsy. Neurology, 60(3), 426- 431.

Meletti, Stefano, Benuzzi, F., Cantalupo, G., Rubboli, G., Tassinari, C. A., \& Nichelli, P. (2009). Facial emotion recognition impairment in chronic temporal lobe epilepsy. Epilepsia, 50(6), 1547- 1559. https://doi.org/10.1111/j.1528-1167.2008.01978.x

Micoulaud-Franchi`, J.-A., Bartolomei, F., Duncan, R., \& McGonigal, A. (2017). Evaluating quality of life in epilepsy: The role of screening for adverse drug effects, depression, and anxiety. Epilepsy \& Behavior, J/75, 18- 24 . https://doi.org/10.1016/j.yebeh.2017.07.016

Micoulaud-Franchi, J.-A., Kotwas, I., Lanteaume, L., Berthet, C., Bastien, M., Vion-Dury, J., ... Bartolomei, F. (2014). Skin conductance biofeedback training in adults with drugresistant temporal lobe epilepsy and stress-triggered seizures: A proof-of-concept study. Epilepsy \& Behavior, 41, 244-250. https://doi.org/10.1016/j.yebeh.2014.10.017

Myers, L., Lancman, M., Laban-Grant, O., Matzner, B., \& Lancman, M. (2012). Psychogenic non-epileptic seizures: Predisposing factors to diminished quality of life. Epilepsy \& Behavior,25(3), 358- 362. https://doi.org/10.1016/j.yebeh.2012.08.024

Nagai, Y., Critchley, H. D., Rothwell, J. C., Duncan, J. S., \& Trimble, M. R. (2009). Changes in Cortical Potential Associated With Modulation of Peripheral Sympathetic Activity in Patients With Epilepsy. Psychosomatic Medicine, 71(1), 84. https://doi.org/10.1097/PSY.0b013e31818f667c

Nagai, Y., Goldstein, L. H., Critchley, H. D., \& Fenwick, P. B. C. (2004). Influence of sympathetic autonomic arousal on cortical arousal: implications for a therapeutic 
behavioural intervention in epilepsy. Epilepsy Research, 58(2-3), 185-193. https://doi.org/10.1016/j.eplepsyres.2004.02.004

O’Brien, F. M., Fortune, G. M., Dicker, P., O’Hanlon, E., Cassidy, E., Delanty, N., ... Murphy, K. C. (2015). Psychiatric and neuropsychological profiles of people with psychogenic nonepileptic seizures. Epilepsy \& Behavior, 43, 39-45. https://doi.org/10.1016/j.yebeh.2014.11.012

Oliveira, G. N. M. de, Araujo Filho, G. M. de, Kummer, A., Salgado, J. V., Portela, E. J., Sousa-Pereira, S. R., \& Teixeira, A. L. (2011). Beck depression inventory (BDI) and hamilton rating scale for depression (HAM-D) in patients with epilepsy. Jornal Brasileiro de Psiquiatria, 60(2), 131-134, https://doi.org/10.1590/S004720852011000200008

Oosterhuis, A. (1999). Coping with epilepsy: the effect of coping styles on self-perceived seizure severity and psychological complaints. Seizure, 8(2), 93-96.

Pick, S., Mellers, J. D. C., \& Goldstein, L. H. (s. d.). Autonomic and subjective responsivity to emotional images in people with dissociative seizures. Journal of Neuropsychology, 12(2), 341 - 355. https://doì.org/10.1111/jnp.12144

Poh, M.-Z., Loddenkemper, T., Reinsberger, C., Swenson, N. C., Goyal, S., Madsen, J. R., \& Picard, R.W. (2012). Autonomic changes with seizures correlate with postictal EEG suppression, Neurology, 78(23), 1868-1876.

Prete, G., Capotosto, P., Zappasodi, F., \& Tommasi, L. (2018). Contrasting hemispheric asymmetries for emotional processing from event-related potentials and behavioral responses. Neuropsychology, 32(3), 317-328. https://doi.org/10.1037/neu0000443

Rawlings, G. H., Brown, I., \& Reuber, M. (2017). Predictors of health-related quality of life in patients with epilepsy and psychogenic nonepileptic seizures. Epilepsy \& Behavior, 68, 153- 158. https://doi.org/10.1016/j.yebeh.2016.10.035 
Reuber, M., Jamnadas-Khoda, J., Broadhurst, M., Grunewald, R., Howell, S., Koepp, M., ... Walker, M. (2011). Psychogenic nonepileptic seizure manifestations reported by patients and witnesses. Epilepsia, 52(11), 2028- 2035. https://doi.org/10.1111/j.15281167.2011.03162.x

Reynaud, E., El-Khoury-Malhame, M., Blin, O., \& Khalfa, S. (2012). Voluntary Emotion Suppression Modifies Psychophysiological Responses to Films. Journal of Psychophysiology, 26(3), 116- 123. https://doi.org/10.1027/0269-8803/a000074

Roberts, N. A., \& Reuber, M. (2014). Alterations of consciousness in psychogenic nonepileptic seizures: emotion, emotion regulation and dissociation. Epilepsy \& Behavior: $E \& B, 30,43$ - 49. https://doi.org/10.1016/j.yebeh.2013.09.035

Sarchiapone, M., Gramaglia, C., Iosue, M., Carli, V., Mandelli, L., Serretti, A., ... Zeppegno, P. (2018). The association between electrodermal activity (EDA), depression and suicidal behaviour: A systematic review and narrative synthesis. BMC Psychiatry, 18(1). https://doi.org/10.1186/s12888-017-1551-4

Saylik, R., Raman, E., \& Szameitat, A. J. (2018). Sex Differences in Emotion Recognition and Working Memory Tasks. Frontiers in Psychology, 9, 1072. https://doi.org/10.3389/fpsyg.2018.01072

Schäflein, E., Sattel, H., Schmidt, U., \& Sack, M. (2018). The enemy in the mirror: selfperception-induced stress results in dissociation of psychological and physiological responses in patients with dissociative disorder. European Journal of Psychotraumatology, 9(Suppl 3). https://doi.org/10.1080/20008198.2018.1472991

Schneíder, D., Regenbogen, C., Kellermann, T., Finkelmeyer, A., Kohn, N., Derntl, B., ... Habel, U. (2012). Empathic behavioral and physiological responses to dynamic stimuli in depression. Psychiatry Research, 200(2-3), 294- 305. https://doi.org/10.1016/j.psychres.2012.03.054 
Sevcencu, C., \& Struijk, J. J. (2010). Autonomic alterations and cardiac changes in epilepsy. Epilepsia, 51(5), 725- 737. https://doi.org/10.1111/j.1528-1167.2009.02479.x

Smith, S. D., \& Bulman-Fleming, M. B. (2005). An examination of the right-hemisphere hypothesis of the lateralization of emotion. Brain and Cognition, 57(2), 210-213. https://doi.org/10.1016/j.bandc.2004.08.046

Spielberger, C. D., \& Vagg, P. R. (1984). Psychometric properties of the STAI: a reply to Ramanaiah, Franzen, and Schill. Journal of Personality Assessment, 48(1), 95- 97.

Szaflarski, J. P. J., Szaflarski, M. M., Hughes, C. C., Ficker, D. M. D., Cahill, W. T. W., \& Privitera, M. D. M. (2003). Psychopathology and quality of life: psychogenic nonepileptic seizures versus epilepsy. Medical Science Monitor, 9(4), CR113-CR118.

Vazquez, B., \& Devinsky, O. (2003). Epilepsy and anxiety. Epilepsy \& Behavior, 4, 20- 25. https://doi.org/10.1016/j.yebeh.2003.10.005

Yamada, M., Murai, T., Sato, W., Namiki, C., Miyamoto, T., \& Ohigashi, Y. (2005). Emotion recognition from facial expressions in a temporal lobe epileptic patient with ictal fear. Neuropsychologia, 43(3), 434- 441. https://doi.org/10.1016/j.neuropsychologia.2004.06.019 


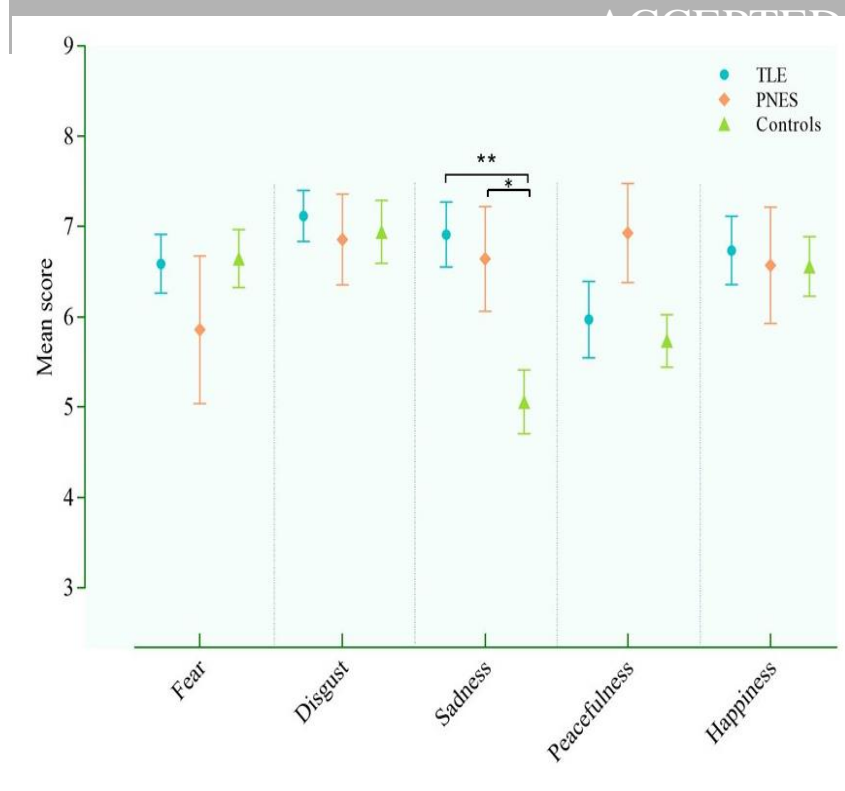

A

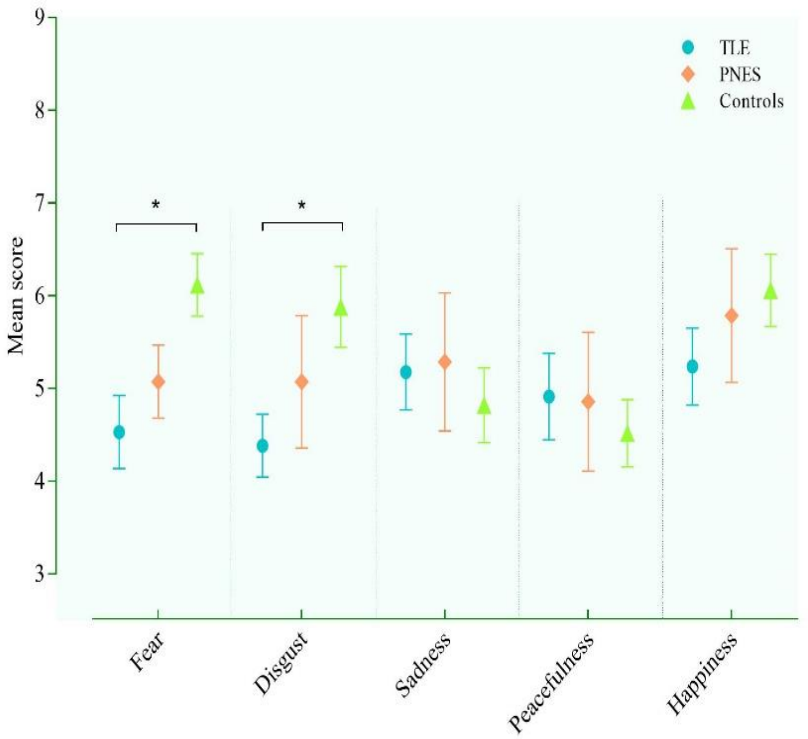

B Suppression condition

Fig.1 : Plots of the subjective evaluation of emotional intensity of the three populations (TLE in blue, PNES in orange, Controls in green) as a function of the various emotions in both task conditions (left/A : attention condition; right/B : suppression condition. Means and standard error bars are reported).

$* p=0.05 ; * * p<0.001$

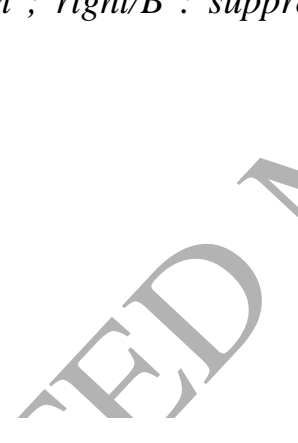

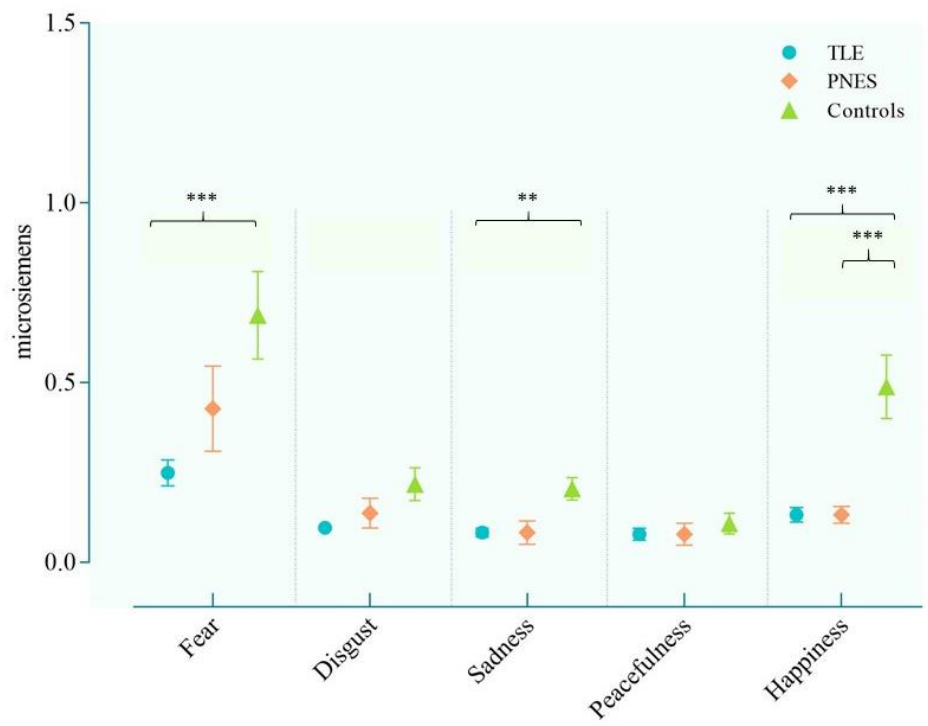

A

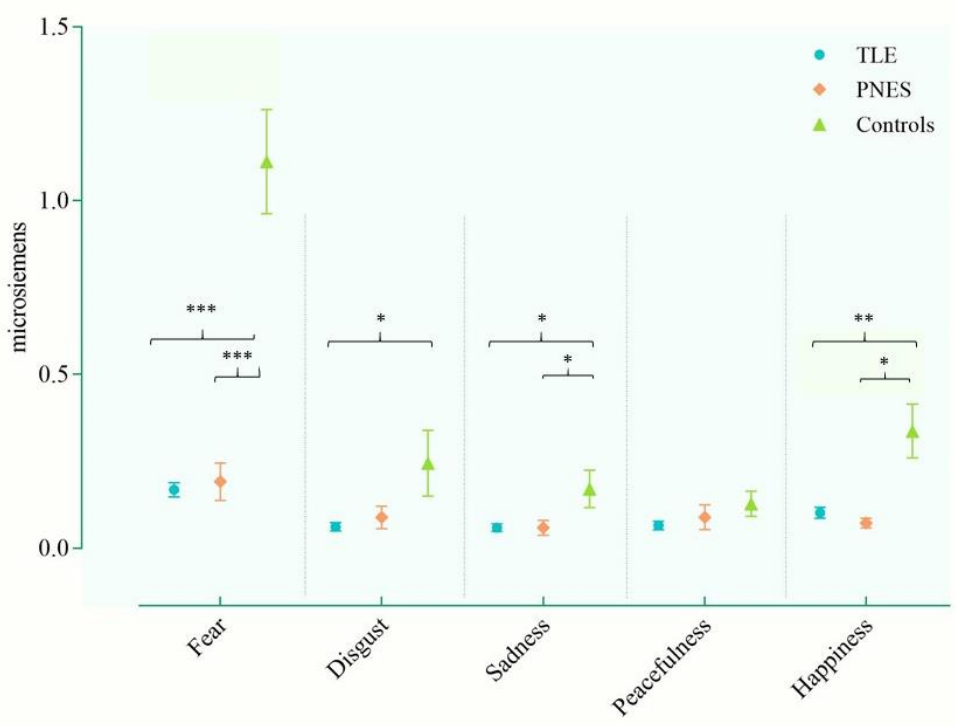


Fig.2 : Plots of the mean amplitude of electrodermal responses of the three populations (TLE in blue, PNES in orange, Controls in green) as a function of the various emotions in both task conditions (left/A : attention condition ; right/B : suppression condition. Means and standard error bars are reported).

* $p=0.05 ; * * p<0.001$

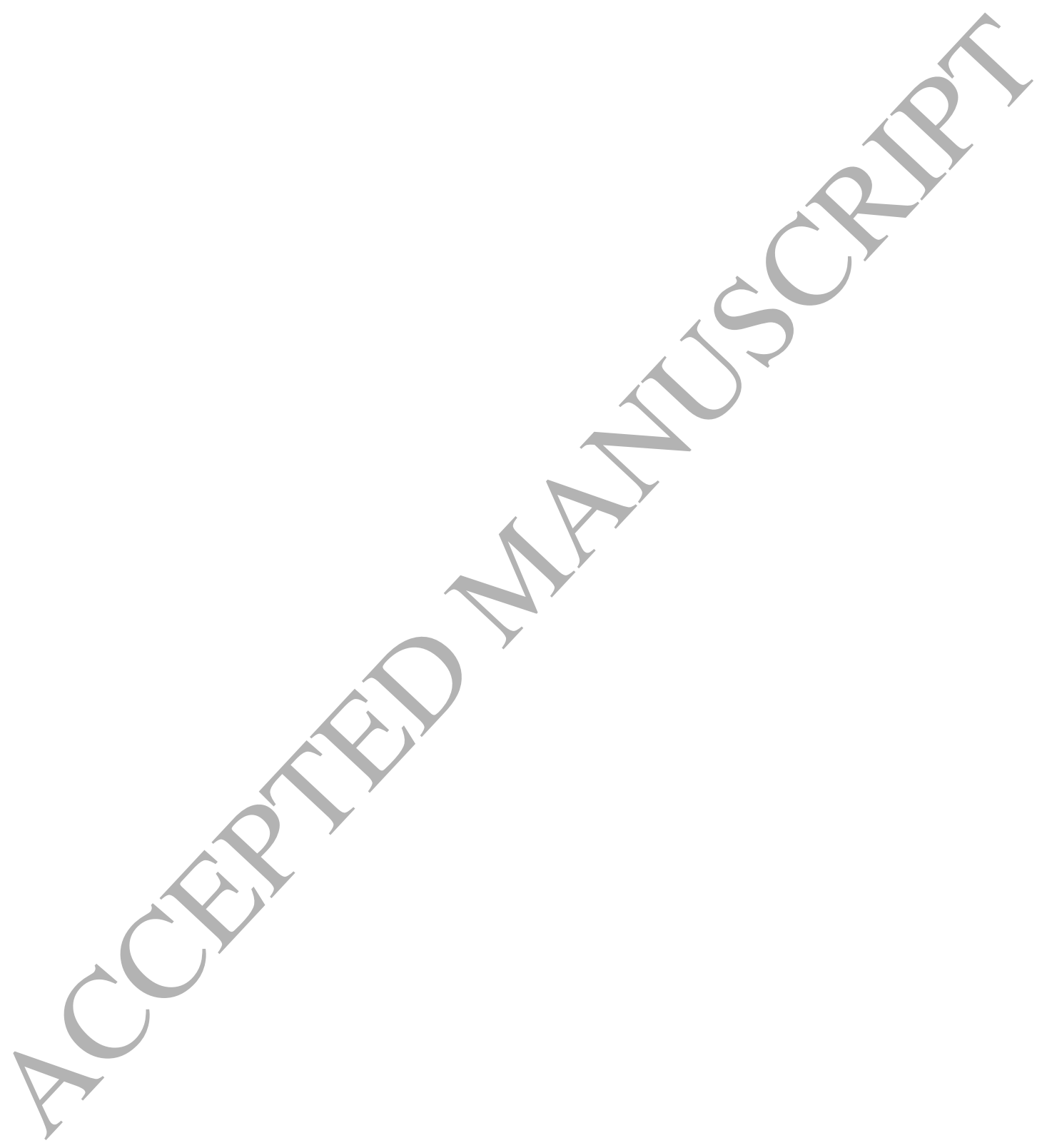


Table 1. Demographic and clinical characteristics

TLE group $(n=34) \quad$ PNES group $(n=14)$

Control group $(\mathrm{n}=34)$

Gendre

$$
\text { Age }
$$

Female $20(59 \%)$

Male $14(41 \%)$

Age

$$
37,56(10.82)
$$

Age of onset (epilepsy or PNES)

Laterality epilepsy

$$
\begin{aligned}
\text { Left } & 19 / 34(56 \%) \\
\text { Right } & 11 / 34(32 \%) \\
\text { Bilateral } & 4 / 34(12 \%)
\end{aligned}
$$

Medication

Carbamazepine 7/34 (20\%)
Clonazepam 3/34 (9\%)
Clobazam 6/34 (18\%)
Citalopram 1/34 (3\%)
Eslicarbazepin acetate 5/34 (15\%)
Fluoxetine 1/34 (3\%)
Lacosamide 9/34 (26\%)
Levetiracetam 9/34(26\%)
Lamotrigine 11/34 (32\%)
Oxcarbazepine 2/34 (6\%)
Pregabalin 4/34 (12\%)
Phenytoin 2/34 (6\%)
Topiramate 2/34 (6\%)
Perampanel 5/34 (15\%)
Vigabatrin 1/34 (3\%)
Valproic acid 3/34 (9\%)
Zonisamide 4/34 (12\%)

$11(79 \%)$

$24(70 \%)$

$3(21 \%)$

33 (12.79)

$10(30 \%)$

$31,65(10.59)$

$25,60(15.04)$

Agomelatin 1/14 (7\%)

Carbamazepine 2/14 (14\%)

Clonazepam 2/14 (14\%)

Clobazam 2/14 (14\%)

Duloxetine 1/14 (7\%)

Eslicarbazepin acetate 1/14 (7\%)

Levetiracetam 1/14 (7\%)

Nordazepam 1/14 (7\%)

Pregabalin 1/14 (7\%)

Quetiapine fumarate 1/14 (7\%)

Venlafaxin chlorydrate 1/14 (7\%)

Table 2. Statistical comparisons on demographic and clinical characteristics between the three groups. 


\begin{tabular}{llllll} 
TLE $(\mathrm{n}=34)$ & $37.56(10.82)$ & $20 \mathrm{~F} / 14 \mathrm{M}$ & $15.088(8.934)$ & $41.38(13.56)$ & $49(13.72)$ \\
PNES $(\mathrm{n}=14)$ & $32.93(12.88)$ & $11 \mathrm{~F} / 3 \mathrm{M}$ & $17.786(8.239)$ & $46.79(12.801)$ & $48.86(12.955)$ \\
Control (n=34) & $31.65(10.59)$ & $24 \mathrm{~F} / 10 \mathrm{M}$ & $2.794(3.198)$ & $29.94(7.777)$ & $38.76(8.88)$ \\
$P$-Value & & & & & \\
TLE vs Control & 0.503 & 0.310 & $<.001$ & $<.001$ & $<.001$ \\
TLE vs PNES & 0.564 & 0.194 & 0.375 & 0.209 & 0.974 \\
PNES vs Control & 0.748 & 0.572 & $<.001$ & $<.001$ & .003 \\
\hline
\end{tabular}

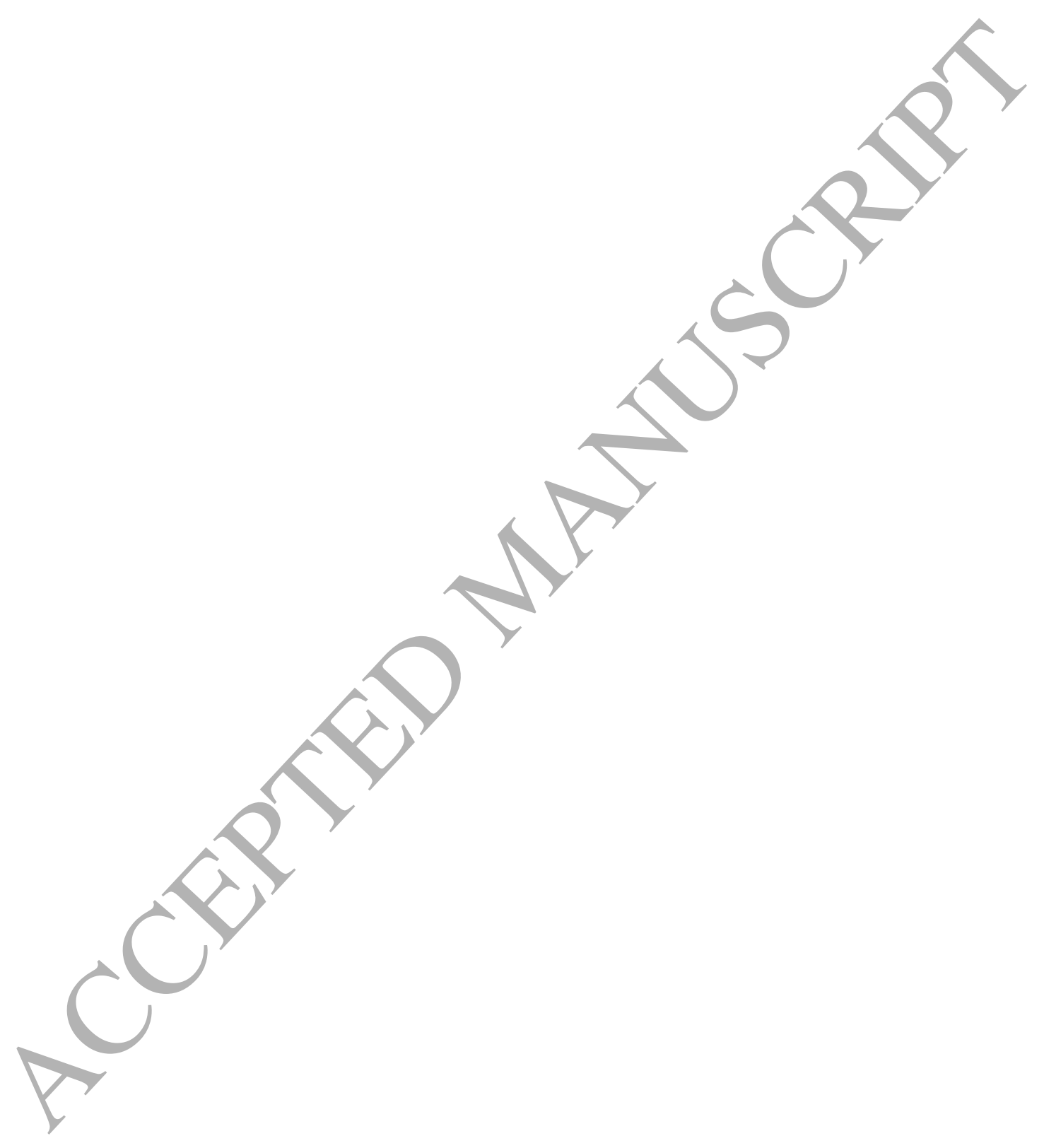

